Research Article

\title{
A GA-Based BP Artificial Neural Network for Estimating Monthly Surface Air Temperature of the Antarctic during 1960-2019
}

\author{
Miao Fang (10 \\ Northwest Institute of Eco-Environment and Resource, Chinese Academy of Sciences, Lanzhou 730000, China \\ Correspondence should be addressed to Miao Fang; mfang@lzb.ac.cn
}

Received 11 April 2021; Revised 12 May 2021; Accepted 1 June 2021; Published 7 June 2021

Academic Editor: Pedro Jiménez-Guerrero

Copyright $\odot 2021$ Miao Fang. This is an open access article distributed under the Creative Commons Attribution License, which permits unrestricted use, distribution, and reproduction in any medium, provided the original work is properly cited.

\begin{abstract}
The spatial sparsity and temporal discontinuity of station-based SAT data do not allow to fully understand Antarctic surface air temperature (SAT) variations over the last decades. Generating spatiotemporally continuous SAT fields using spatial interpolation represents an approach to address this problem. This study proposed a backpropagation artificial neural network (BPANN) optimized by a genetic algorithm (GA) to estimate the monthly SAT fields of the Antarctic continent for the period 1960-2019. Cross-validations demonstrate that the interpolation accuracy of GA-BPANN is higher than that of two benchmark methods, i.e., BPANN and multiple linear regression (MLR). The errors of the three interpolation methods feature month-dependent variations and tend to be lower (larger) in warm (cold) months. Moreover, the annual SAT had a significant cooling trend during 1960-1989 (trend $=-0.07^{\circ} \mathrm{C} /$ year; $p=0.04$ ) and a significant warming trend during $1990-2019$ (trend $=0.06^{\circ} \mathrm{C} /$ year; $p=0.05$ ). The monthly SAT did not show consistent cooling or warming trends in all months, e.g., SAT did not show a significant cooling trend in January and December during 1960-1989 and a significant warming trend in January, June, July, and December during 1990-2019. Furthermore, the Antarctic SAT decreases with latitude and the distance away from the coastline, but the eastern Antarctic is overall colder than the western Antarctic. Spatiotemporal inconsistencies on SAT trends are apparent over the Antarctic continent, e.g., most of the Antarctic continent showed a cooling trend during 1960-1989 (trend $=-0.20 \sim 0^{\circ} \mathrm{C} /$ year; $p=0.01 \sim 0.27$ ) with a peak over the central part of the eastern Antarctic continent, while the entire Antarctic continent showed a warming trend during $1990-2019$ (trend $=0 \sim 0.10^{\circ} \mathrm{C}$ /year; $p=0.04 \sim 0.42$ ) with a peak over the higher latitudes.
\end{abstract}

\section{Introduction}

Variation in surface air temperature (SAT) over the Antarctic is an indicator of global SAT change [1]. Variations in the Antarctic SAT partly contribute to climate anomalies in East Asia [2], Tropics [3], and Arctic [4] through the atmosphere-ocean bridges. Establishing how the Antarctic SAT modulates the sea ice extent and thickness over the Southern Hemisphere will improve the predictability of global climate change. However, challenges exist in understanding the Antarctic SAT, and previous studies have not reached consistent conclusions. Some studies have reported that most of the Antarctic continent has shown a cooling trend [5-7]. In contrast, other studies support a weak warming trend over the entire Antarctic continent [8-10]. In addition, some studies have reported that the
Antarctic Peninsula showed a warming trend during the last decades of the twentieth century $[11,12]$, but other research suggested that there was no evidence that the Antarctic Peninsula has experienced warming during that period [13]. Among the factors responsible for the inconsistent study results are the sparsity and temporal discontinuity of stationbased SAT data [14], the lack of good quality satellite-based SAT products, which are often affected by cloud cover and snow surface over the Antarctic [15], the large warm bias in reproducing the Antarctic temperature using climate models [16], the clear cold bias for monthly SAT reanalysis datasets over the Antarctic coastal regions, and the large warm bias dominating the winter over the Antarctic inland [17]. The above inconsistencies may also be attributed to the different data sources used for each study. Accordingly, generating a widely accepted, high-quality, and spatiotemporally 
continuous SAT dataset over the Antarctic is critical to better understand the Antarctic SAT variation during the last decades.

An alternative approach is used to generate spatiotemporally continuous and high-quality SAT data based on limited station-based SAT observations and appropriate spatial interpolation methods [18, 19], which allows exploring the SAT variations over the areas where stationbased data are not available. There are many spatial interpolation methods such as inverse distance weighting (IDW) [20], Spline method [21], Kriging-based method [22], and multiple linear regression method [23]. Based on these methods, several gridded SAT datasets have been developed, such as the Met Office Hadley Centre Climatic Research Unit Temperature version 4 (hereinafter, HadCRUT4) [24], Berkeley Earth Surface Temperatures (hereinafter, BEST) [25], NASA GISS Surface Temperature Analysis (hereinafter, GISTEMP) [26], NOAA Merged Land-Ocean Global Surface Temperature Analysis version 4 (MLOST) [27], and Climatic Research Unit Timeseries version 4 (CRU TS) [28]. However, although these SAT datasets have been widely used in various climate studies, shortcomings persist. For example, these datasets do not cover some crucial regions, and there are large areas of missing values over the ocean and the Antarctic [29]. These shortcomings motivated this research to establish new approaches to create gridded SAT datasets covering the entire Antarctic and meeting high-quality standards.

In recent years, machine learning- (ML-) based spatial interpolation methods have been proposed over traditional methods (e.g., IDW, Spline, and Kriging) [30-33]. The feedforward backward-propagation artificial neural network (BPANN) [34], which is a commonly used ANN model in $\mathrm{ML}$, is a promising tool for solving complex nonlinear modelling and prediction problems [35]. As a type of nonlinear model, BPANN can find the complex nonlinear relationships within the sample data without assuming a specific relationship between the input and output in advance [34]. The BPANN algorithm has been used in the spatial interpolation of climate variables [36-38]. However, due to its purely data-driven characteristics, BPANN also showed deficiencies in practice. For example, BPANN is prone to overfitting [39] and can easily fall into local optimal solutions [40]. In addition, the structure of BPANN cannot be easily determined, and while the selection of the initial connection weights and thresholds of the network greatly impacts BPANN's performance, they are random and cannot be accurately obtained [41]. Aiming to overcome these intrinsic deficiencies, many researchers have attempted to improve BPANN's performance using intelligent optimization algorithms [42-45]. Genetic algorithms (GA) feature excellent global search ability [46] and are used to optimize the initial connection weights and thresholds of BPANN (hereinafter, GA-BPANN) in order to avoid falling into a local optimum and improve its training speed and modelling ability $[42,47]$. Therefore, GA-BPANN has been applied in many fields of natural and social sciences for complex nonlinear modelling and prediction, showing excellent performance over other BPANN models optimized by different algorithms [48-51]. Currently, however, there are very few reports on the use of GA-BPANN for spatial interpolation, especially for the interpolation of Antarctic temperatures.

A high-quality and spatiotemporally continuous SAT dataset is the foundation of Antarctic climate research. This study aims to produce a monthly gridded SAT dataset for the Antarctic continent during 1960-2019 using the GA-BPANN method and limited station-based SAT observations. The performance of the GA-BPANN for spatial interpolation is compared with those of MLR and BPANN. The remainder of the paper is organized as follows. The details of the stationbased SAT data and the spatial interpolation methods used in this study are presented in Section 2. Section 3 includes the validation of the estimated Antarctic SAT datasets using different interpolation methods. Preliminary analyses regarding the spatiotemporal variations of the Antarctic SAT during 1960-2019 are also described in this section. Some prospects for improving the data quality of the SAT interpolation are discussed in Section 4. In the final section, the main findings of this study are summarized.

\section{Data and Methods}

2.1. Station-Based SAT Data. The station-based SAT data of the Antarctic were extracted from the Global Historical Climatology Network monthly dataset, version 4 (hereinafter, GHCNmV4) [52]. The GHCNmV4 is a set of monthly climate records from thousands of weather stations around the world. The monthly data have periods of record that vary by station, with the earliest observations dating to the eighteenth century. Some station records are purely historical and are no longer updated, whereas many others are still up to date. Relative to previous versions, the GHCNmV4 provides an expanded dataset of station-based temperature records as well as more comprehensive uncertainties for the calculation of station and regional temperature trends. The total number of monthly temperature stations in GHCNmV4 over the Antarctic during 1960-2019 is 82 (Figure 1).

2.2. Geographic Factor Data. The geographic factors affecting the spatial distribution of SAT mainly include longitude, latitude, altitude, topographic conditions, and land cover [53]. Previous studies have reported that the monthly mean SAT has a significant correlation with latitude, longitude, and altitude [54, 55]. In addition, the spatial distribution of SAT at the continental scales is mainly controlled by geographic factors such as latitude, longitude, and elevation [54]. These three factors usually are extracted from digital elevation model (DEM) data. In this study, a $1 \mathrm{~km}$ resolution Antarctic DEM data was used; these data were downloaded from the National Tibetan Plateau Data Centre (TPDC; https://data.tpdc.ac.cn/en/). This $1 \mathrm{~km}$ resolution DEM can well capture the striking effect of Antarctic orography on SAT distributions. The elevation of each SAT station was extracted based on the longitude and latitude of this SAT station. The training sample used to construct the spatial interpolation model includes the longitudes and 


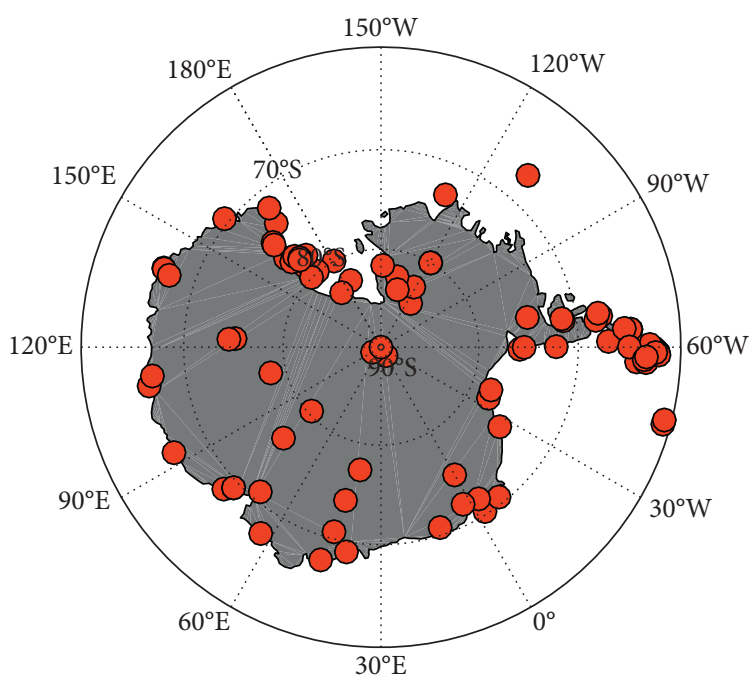

(a)

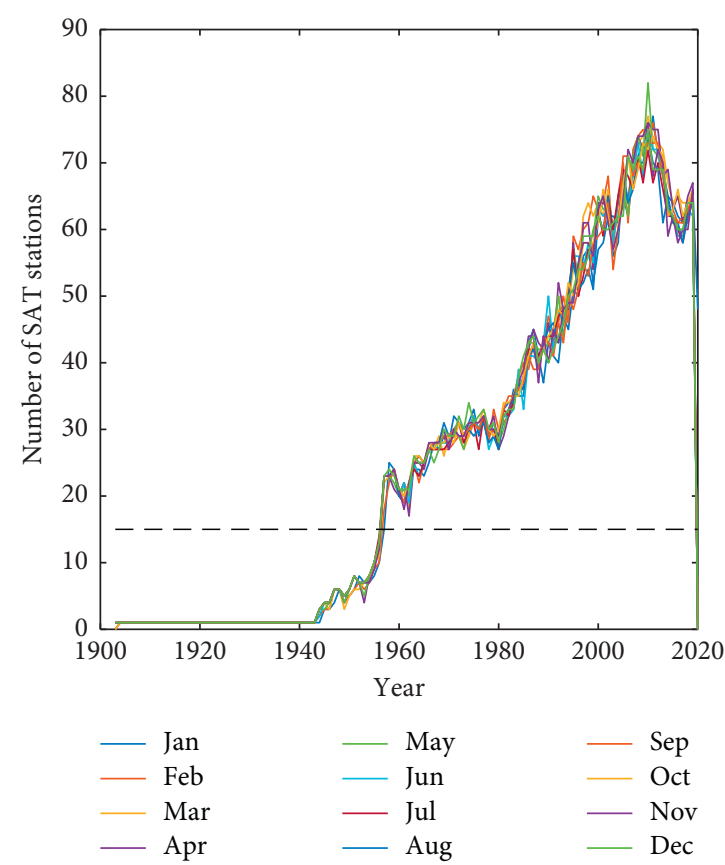

(b)

FIgURE 1: The spatiotemporal distribution of the extracted station-based SAT data of the Antarctic.

latitudes of all SAT stations, the extracted elevations, and the monthly SAT observations during 1960-2019. The interpolation model was constructed monthly using the training sample. Additionally, the longitudes, latitudes, and elevations on all grids were obtained through DEM sampling in ArcGIS software and then were used as the input sample of the monthly varied interpolation model for estimating the monthly SAT fields of the Antarctic continent during 1960-2019. Therefore, the spatial resolution of the estimated SAT fields is consistent with that of DEM, both of which are $1 \mathrm{~km}$ regular grids.

\subsection{Spatial Interpolation Methods}

2.3.1. MLR. Multiple linear regression (MLR) is a commonly used method in spatial interpolation, and its performance is always superior to several benchmark interpolation methods such as IDW, Spline, and Kriging [23]. In this study, the MLR-based interpolation result is considered as a reference to compare the interpolation performances of the BPANN and GA-BPANN. According to previous studies, the MLR method considers that the spatial distribution of SAT is the comprehensive effect of longitude, latitude, altitude, and other geographic factors. MLR takes SAT as the dependent variable and geographic factors such as altitude, latitude, and longitude as independent variables $[20,56]$ to construct the SAT interpolation model as follows:

$$
T=a x_{1}+b x_{2}+c x_{3}+\varepsilon,
$$

where $T$ denotes SAT and $x_{1}, x_{2}, x_{3}$ are longitude, latitude, and altitude, respectively. $\varepsilon$ is the residual error. $a, b, c$ are regression coefficients. The regression coefficients and residual error are estimated by the least square method. The MLR model is constructed, and then the SAT over other areas is estimated based on the constructed MLR model and the longitudes, latitudes, and altitudes extracted from the DEM data.

2.3.2. BPANN. The BPANN model is one of the most commonly used ANN models and has strong nonlinear modelling and analysis capability for complex systems. BPANN uses a nonlinear differentiable function to train a multilayer network, which is divided into input layer, hidden layer, and output layer. BPANN features several advantages, including (1) simple structures and easy operability, (2) sophisticated nonlinear mapping from input to output, and (3) self-study ability for further improvement and development [57]. In this study, there were three neurons in the input layer of the BPANN model to denote the longitude, latitude, and altitude and one neuron in the output layer (i.e., the SAT). The number of neurons in the hidden layer is a fundamental parameter of the BPANN model, but it is difficult to determine exactly. Currently, empirical rules for addressing this problem have been proposed [58]. In this study, the neurons of the hidden layer were set to seven according to these rules. The structure of BPANN is described in Figure 2 and takes the following formulation:

$$
\text { SAT }=\text { BPANN }(\text { lontitude, latitude, altitude, } \theta)+\varepsilon,
$$

where $\varepsilon$ is the residual error and $\theta$ denotes the parameters of the BPANN model such as connection weights and thresholds. 


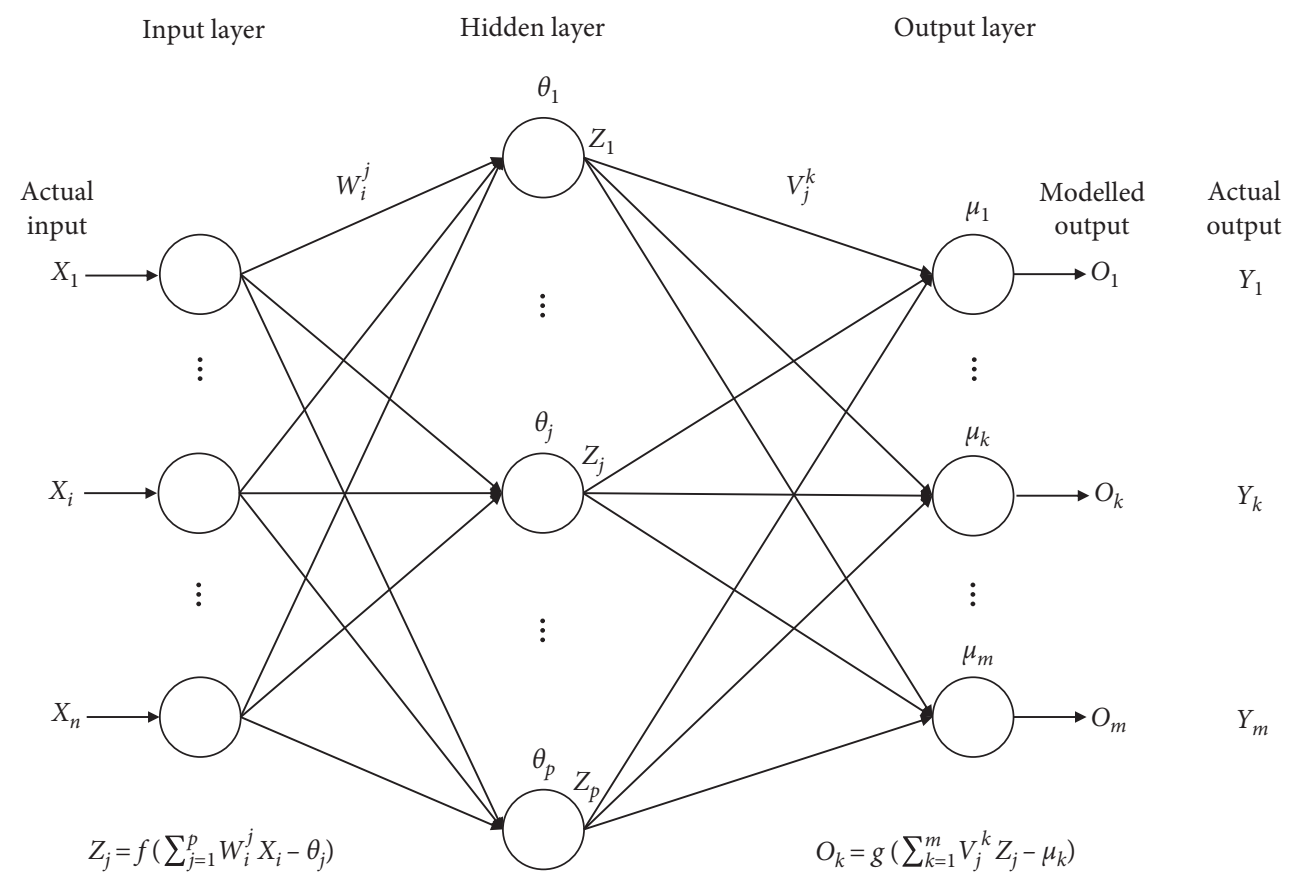

Figure 2: The structure of the BPANN model. The number of neurons of each layer is denoted as $n, p$, and $m$, respectively. $W_{i}^{j}(i=1,2, \ldots, n$ and $j=1,2, \ldots, p)$ represents the weights between the input and hidden layer, while $V_{j}^{k}(j=1,2, \ldots, p$ and $k=1,2, \ldots, m)$ represents the weights between the hidden and the output layer. The threshold values of the hidden layer and the output layer are $\theta_{j}$ and $\mu_{k}$, respectively. $f$ $(\cdot)$ is an activation function by which the mapping process from the input layer to the hidden layer is implemented and $g(\cdot)$ is an activation function by which the mapping process from the hidden layer to the output layer is implemented. In this study, the default activation functions of the BPANN model in the MATLAB (2016a) ANN toolbox were adopted. The parameters in the BPANN mainly include the maximum training times, learning rate, and training target accuracy. The parameters of the BPANN model in this study include a maximum training time of 2000, a learning rate of 0.5 , and a training target accuracy of 0.001 .

2.3.3. GA-BPANN. A GA is a kind of self-adaptive and probabilistic global searching process that starts from an initial population of finite string representations in which each member (called chromosome or individual) represents a candidate solution to the problem [46]. The initial population of a GA is randomly sampled. A GA provides a solution space that enables BPANN to find the optimal solution that helps avoid a local optimum. In GA-BPANN, each individual (or chromosome) represents a distribution of connection weights and thresholds of each network. Thus, a population of individuals (or chromosomes) represents a population of neural networks with different weights and threshold distributions. A GA is used to optimize the initial weights and thresholds of BPANN. The BPANN model optimized by GA includes two parts. One part is to determine the BPANN structure and code the initial individuals. The other part is to optimize BPANN with GA. The GA process is summarized as follows: (1) initialize the population; (2) calculate the fitness value of each individual in the population; (3) select individuals which will enter the next generation according to a rule determined by individual fitness values; (4) perform crossover operation according to crossover probability; (5) carry out mutation operation according to mutation probability; (6) if the end conditions are not met, then go to step (2), or enter (7); and (7) use the individual (or chromosome) with the best fitness value in the output population as the optimal solution of the problem. As a result, the most optimal individual, which represents the optimal initial weights and thresholds of the BPANN model, is generated. Figure 3 describes the flowchart of BPANN optimized with GA; for the details of population initialization, fitness function, selection operation, crossover operation, and for mutation operation, refer to $[46,47]$.

2.4. Validation Method. Cross-validation was used to evaluate the spatial interpolation performances of the above three interpolation methods. The cross-validation assumes that the SAT value of each station is unknown and is estimated based on the SAT values of the surrounding stations. The errors between the observed SAT values and the estimated SAT values of all stations are calculated to evaluate the performance of the interpolation method. Typical performance indicators including mean absolute error (MAE) and root-mean-square error (RMSE) were used to investigate the differences between the observed SAT and the estimated SAT. The MAE reflects the extent of the overall error at all sites, while the RMSE can reflect the estimated sensitivity and extreme effect of the error sample data. Smaller values of these two metrics indicate higher accuracy of the interpolation. The formulas for MAE and RMSE are as follows: 
GA

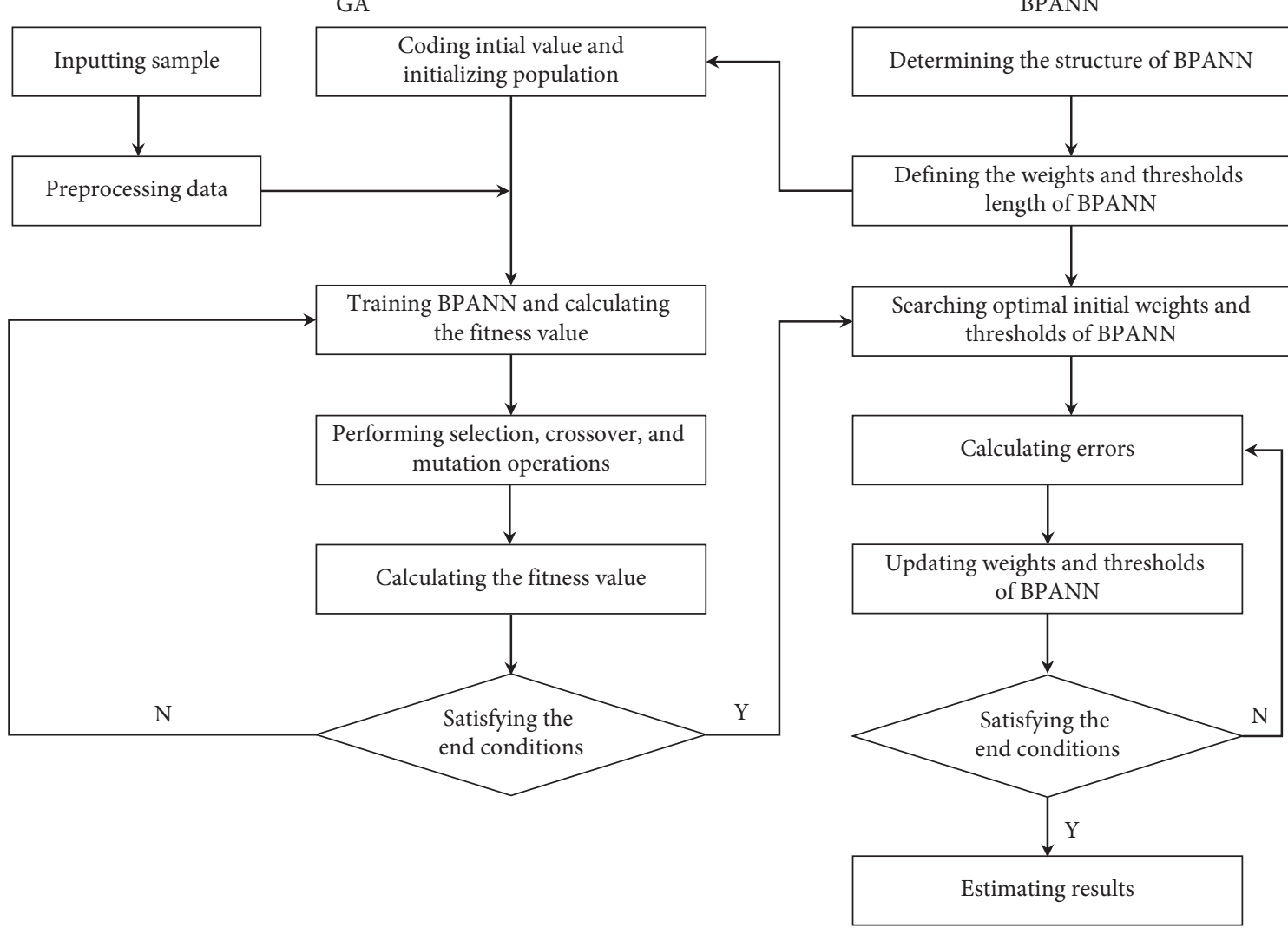

FIGURE 3: Flowchart of BPANN optimized with GA. The parameters in GA mainly include population size, evolutionary times, crossover probability, and mutation probability. In this study, the parameters were set as follows: population size of 100, evolutionary times of 50, crossover probability of 0.4 , and mutation probability of 0.1 . In this study, the GA-BPANN model was constructed with the build-in BP and GA functions in MATLAB (2016a) GA and ANN toolbox.

$$
\begin{aligned}
\text { MAE } & =\frac{1}{n} \sum_{i=1}^{n} a b s\left(T_{o}-T_{e}\right), \\
\text { RMSE } & =\sqrt{\frac{1}{n} \sum_{i=1}^{n}\left(T_{o}-T_{e}\right)^{2},}
\end{aligned}
$$

where $T_{o}$ is the observed value, $T_{e}$ is the estimated value at the corresponding site, and $n$ is the total number of observational sites.

\section{Results}

3.1. Results of Cross-Validations. In this study, 82 stationbased SAT data over the Antarctic continent and its surrounding regions were selected to estimate the monthly SAT fields during the period 1960-2019 using the MLR, BPANN, and GA-BPANN methods. The accuracies of the three interpolation methods were tested by cross-validation. The annual and monthly MAEs and RMSEs were calculated and used to observe the variations of the interpolation accuracies of the three methods (Figures 4 and 5).

Figure 4 reveals a strong monthly dependence of the MAEs and RMSEs associated with the three interpolation methods, i.e., they show larger errors during the cold months and smaller errors during the warm months. Similarly, the validation of SAT reanalysis over the Antarctic demonstrates that the SAT reanalysis datasets have higher MAEs in the Antarctic winter months and lower MAE in the Antarctic summer months [17]. Similar observations have also been reported in the air temperature spatial interpolation for China [59], which found that the interpolation error in winter is larger than that in summer and autumn. In addition, the validation of Arctic air temperature reanalysis datasets also indicated that SAT reanalysis datasets have a large bias in the Arctic winter and a small bias in the Arctic summer [60]. The above results imply that the skill of spatial interpolation for estimating monthly climate variables is temperature-dependent or month-dependent. In addition, Figure 4 suggests that the MAEs and RMSEs between the station-based SAT and the estimated monthly SAT using GA-BPANN are the lowest, with the averaged MAEs at all stations in each month ranging between 1.92 and 4.91 with a mean of 3.15 and the averaged RMSEs at all stations in each month ranging between 4.09 and 9.46 with a mean of 6.31 . Following GA-BPANN is the MLR interpolation method, with station-averaged MAEs in each month ranging from 3.61 to 6.35 and a mean of 5.32 and station-averaged RMSEs in each month ranging from 6.84 to 10.38 and a mean of 9.03. The MAEs and RMSEs associated with BPANN are greater than those of GA-BPANN and MLR, e.g., the station- 


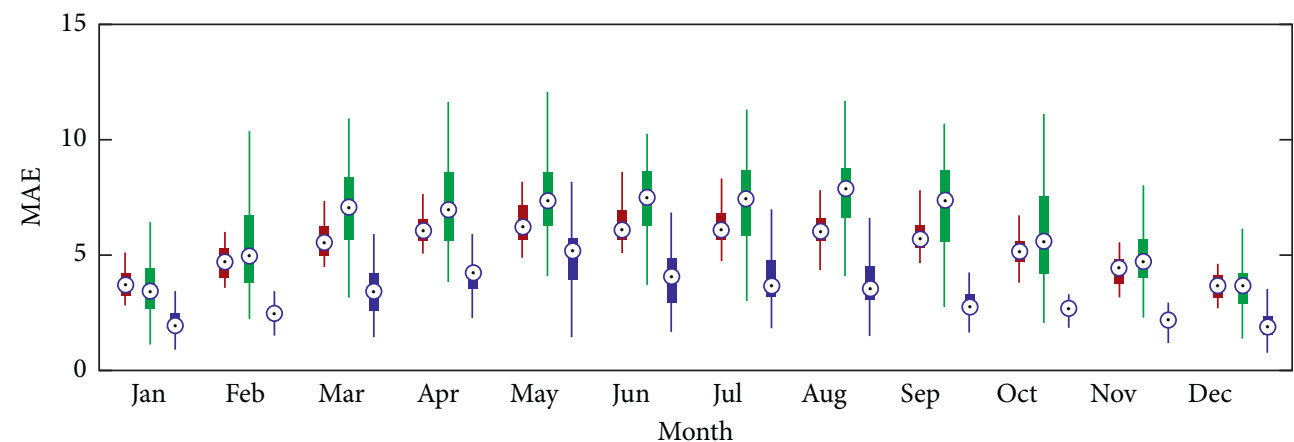

MLR
BPANN
GA-BPANN

(a)

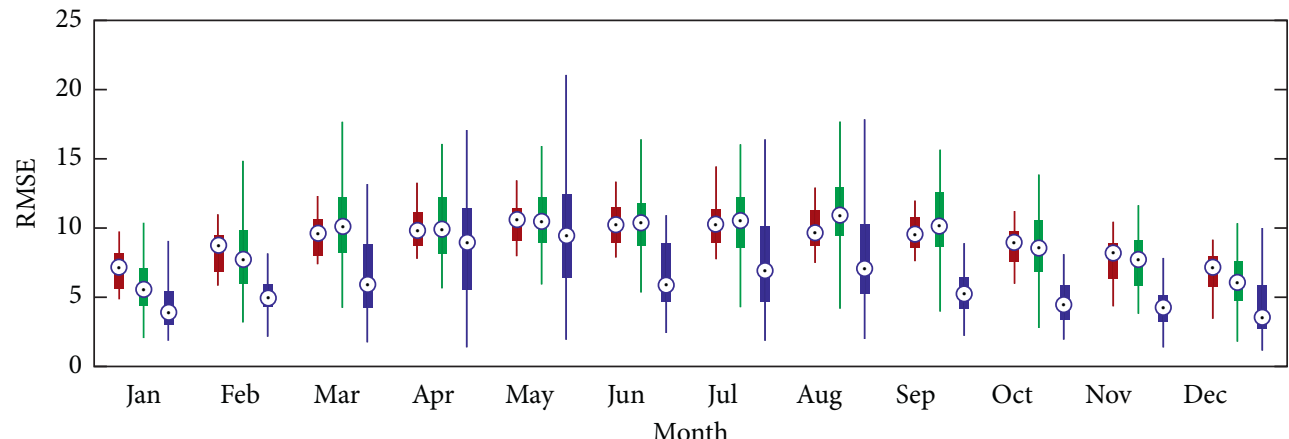

MLR
BPANN
GA-BPANN

(b)

FIGURE 4: Boxplots of the monthly mean absolute errors (MAE) and root-mean-square error (RMSE) of the three interpolation methods for estimating monthly Antarctic SAT during 1960-2019 obtained from the cross-validation.

averaged MAEs in each month range from 3.65 to 8.00 with a mean of 6.28 , and the station-averaged RMSEs in each month range from 5.75 to 12.17 with a mean of 9.30 . Overall, the performance ranking of the three interpolation methods for estimating the monthly SAT of the Antarctic continent is GA-BPANN $>$ MLR $>$ BPANN. Moreover, Figure 5 shows that the interpolation errors of the three methods gradually decrease with the increase of observational data available, implying that when more observational data are used, the relationship between SAT distribution and geographical factors increases, and the interpolation becomes more accurate. Furthermore, Figures 4 and 5 also indicate that the interpolation accuracy of BPANN is inferior to that of MLR, implying that although the BPANN model can express the nonlinear relationship between SAT and geographical factors, without optimal connection weights and thresholds, its performance in the spatial interpolation of the Antarctic SAT is worse than with MLR, which expresses the relationship between SAT and geographical factors in a linear way. In this study, the interpolation accuracy of GA-BPANN is apparently better than that of the MLR and BPANN methods, indicating the effectiveness of the GA optimization for the traditional BPANN.
3.2. Antarctic SAT during 1960-2019. In this section, the temporal and spatial variations of the Antarctic SAT during 1960-2019 were analyzed using the monthly SAT fields generated by the GA-BPANN method.

3.2.1. Temporal Variations of the Antarctic SAT. Since the time span of the estimated SAT fields is 60 years, it includes exactly two climatologies (a 30-year period is a climatology baseline defined by the World Meteorological Organization), i.e., 1960-1989 and 1990-2019, allowing for carrying out SAT climatology comparisons. Therefore, variations of the Antarctic SAT during 1960-1989 and 1990-2019 on monthly and annual timescales are analyzed here (Figure 6). During 1960-1989, the annual mean SAT in the Antarctic continent was $-39.86 \pm 1.24^{\circ} \mathrm{C}$, the highest SAT was found in January (i.e., $-21.62 \pm 1.32^{\circ} \mathrm{C}$ ), and the lowest SAT was found in August (i.e., $-50.53 \pm 2.93^{\circ} \mathrm{C}$ ). During 1990-2019, the annual mean SAT in the Antarctic continent was $-39.31 \pm 0.93^{\circ} \mathrm{C}$. The SAT was highest in December (i.e., $-20.71 \pm 1.24^{\circ} \mathrm{C}$ ) and lowest in August (i.e., $-49.69 \pm 2.59^{\circ} \mathrm{C}$ ). In addition, Figure 6 shows that the Antarctic annual SAT experienced a significant cooling trend during 1960-1989 


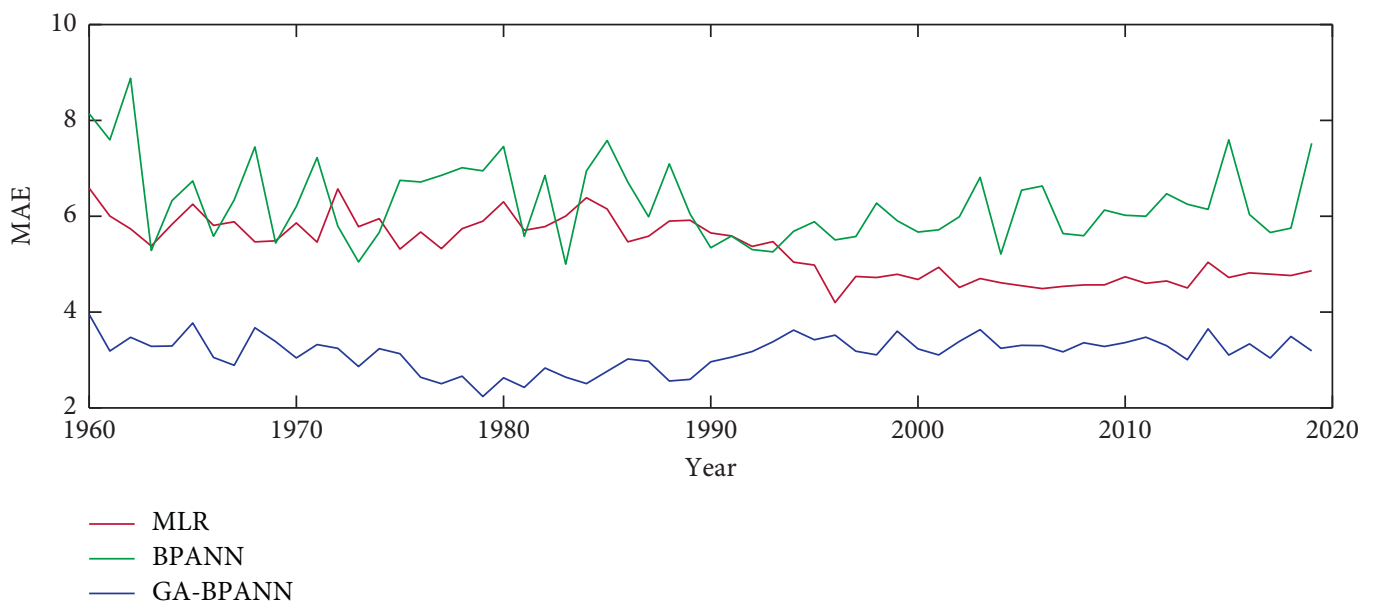

(a)

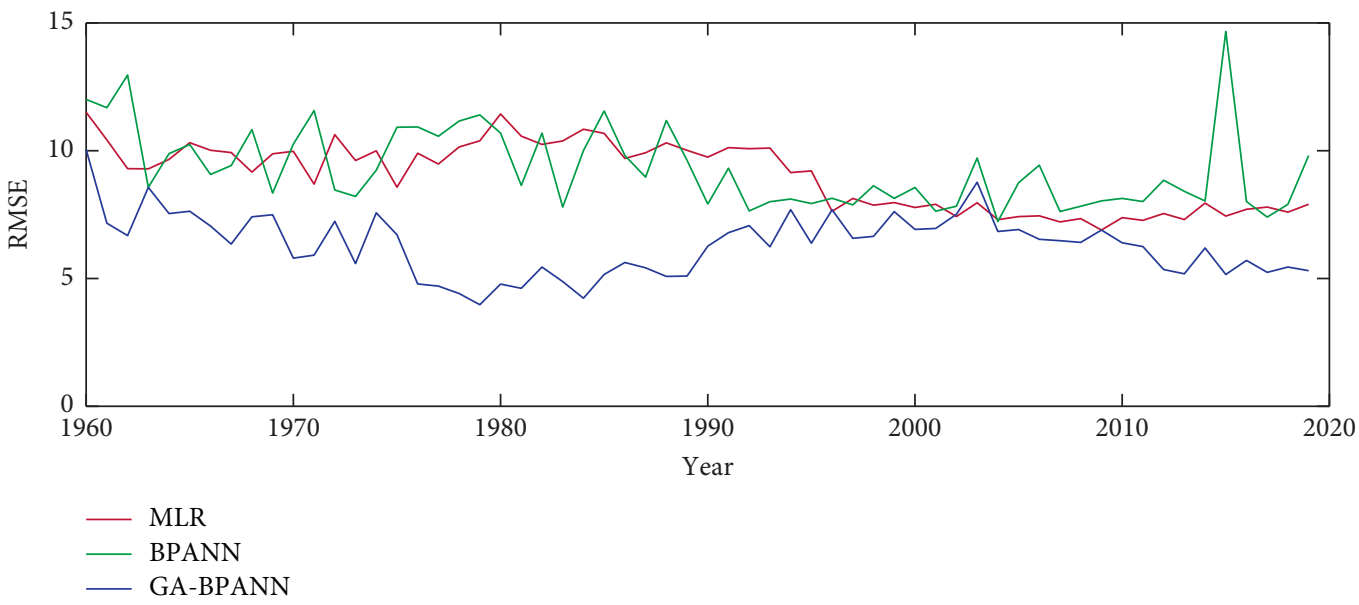

(b)

FIgURE 5: Annual variations of the MAEs and RMSEs associated with the three interpolation methods used for estimating monthly Antarctic SAT during the period 1960-2019. The annual MAE in a year is the average of monthly MAEs at all sites for all months in that year. The annual RMSE was calculated in the same way.

(trend $=-0.07^{\circ} \mathrm{C} /$ year; $p=0.04$ ) and a significant warming trend during 1990-2019 (trend $=0.06^{\circ} \mathrm{C} /$ year; $p=0.05$ ). However, there was no trend in the Antarctic annual SAT during 2003-2019 (trend $=0^{\circ} \mathrm{C} /$ year, $p=0.47$ ). This finding is consistent with the previous conclusion that warming was absent in the Antarctic annual SAT during the last decades of the twenty-first century [13]. Moreover, the monthly SAT did not show a consistent cooling or warming trend in all months during these two periods. For example, the highest cooling rate during 1960-1989 was found in June (trend $=-0.14^{\circ} \mathrm{C} /$ year; $p<0.01$ ), while the SAT had no trend in January during 1960-1989 (trend $=0^{\circ} \mathrm{C} /$ year; $p=0.53$ ), and the SAT in December showed a nonsignificant warming trend during $1960-1989$ (trend $=0.01^{\circ} \mathrm{C} /$ year; $p=0.67$ ). The SAT in other months showed cooling trends with different significant levels and rates during 1960-1989. Furthermore, the warming trends in January, June, July, and November were not significant during 1990-2019. The SAT in December did not show cooling or warming trends (trend $=0^{\circ} \mathrm{C} /$ year; $p=0.44$ ) during 1990-2019. The SAT in other months showed warming trends with different significant levels and rates during 1960-1989. The highest warming rate was in May during $1990-2019$ (trend $=0.16^{\circ} \mathrm{C} /$ year; $p<0.01)$.

3.2.2. Spatial Patterns of the Antarctic SAT. Figure 7 shows the spatial distributions of mean SAT fields during 1960-1989 and 1990-2019, respectively. The two SAT fields show almost identical patterns over the Antarctic continent. The Antarctic SAT basically decreased with the increase of latitude and distance away from the coastline during these two periods, with a cold centre (i.e., $-55.13 \pm 4.67^{\circ} \mathrm{C}$ ) located over the eastern Antarctic continent south of $80^{\circ} \mathrm{S}$. Overall, the east Antarctic continent was colder than the west Antarctic continent during the two periods. Statistical differences between the two SAT fields cannot be found in terms of patterns and amplitudes.

Figure 8 shows the spatial patterns of the SAT trends during 1960-1989 and 1990-2019, respectively. Although 

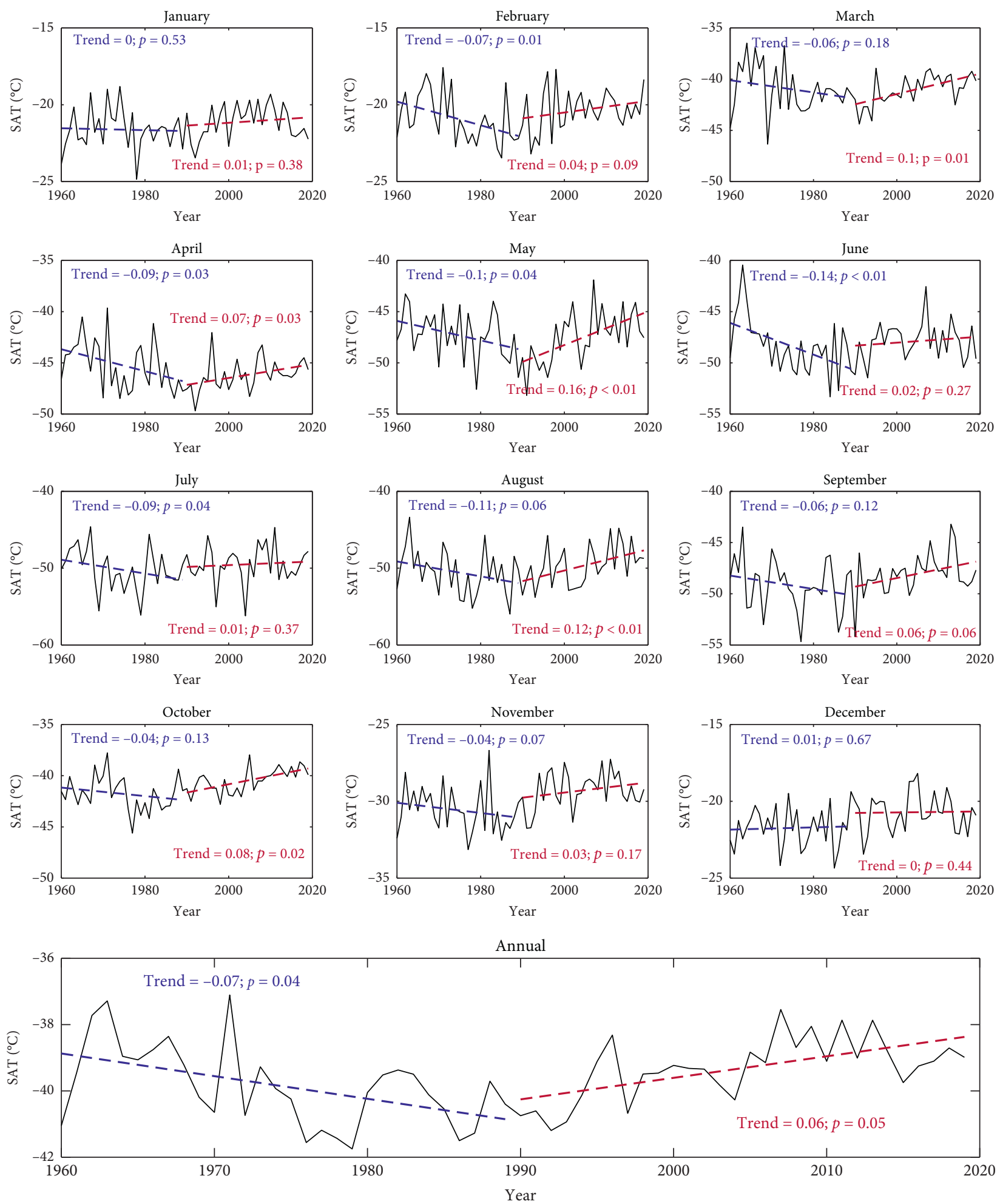

Figure 6: Temporal variations of the Antarctic SAT during 1960-2019 on monthly and annual timescales. The dotted blue and red lines denote the linear trends of the Antarctic SAT during 1960-1989 and 1990-2019, respectively. The trends (unit: ${ }^{\circ} \mathrm{C} /$ year) and their significance (i.e., $p$ values) were calculated using the Mann-Kendall trend test method [61].

the SAT climatology did not show clear differences between the two periods, noticeable differences can be found in the SAT trends during the two periods. Figure 8(a) shows that SAT over most of the Antarctic continent had a cooling trend during 1960-1989 (trend $=-0.20 \sim 0^{\circ} \mathrm{C} /$ year; $p=0.01 \sim 0.27$ ) with a peak over the central part of the eastern Antarctic continent. During the same period, the Antarctic Peninsula also showed a cooling trend 

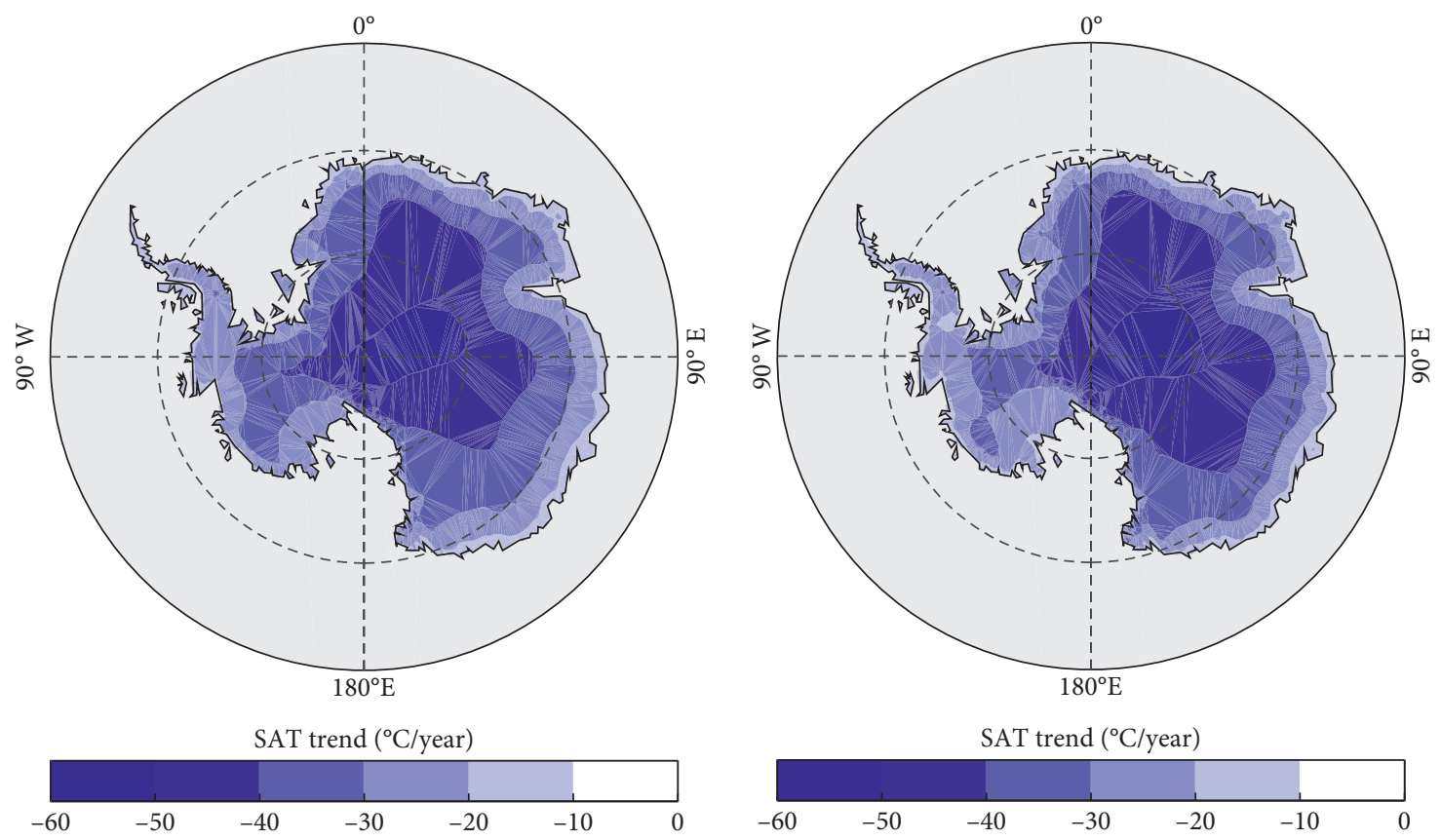

(a)

(b)

FIgURE 7: Spatial distributions of the mean SAT fields during (a) 1960-1989 and (b) 1990-2019, respectively. These two 30-year periods denote two distinct climatologies.

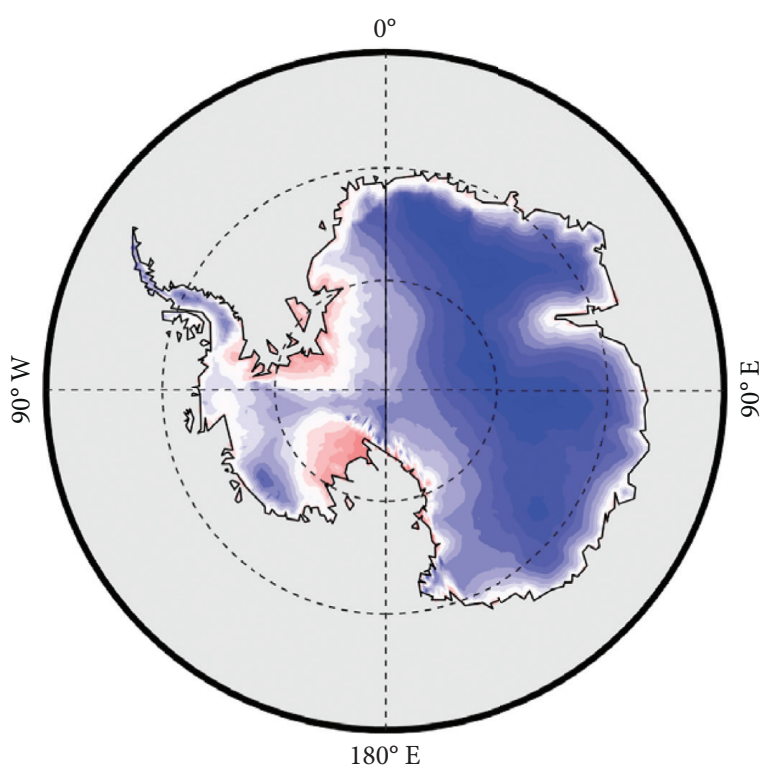

SAT trend $\left({ }^{\circ} \mathrm{C} /\right.$ year $)$

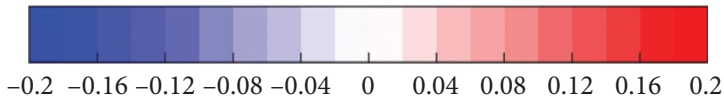

(a)

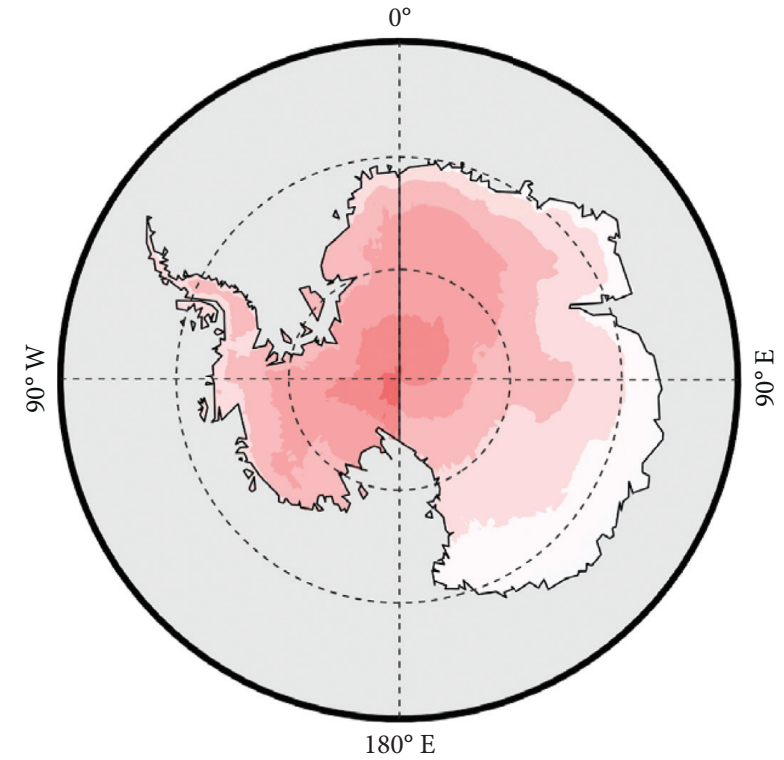

SAT trend $\left({ }^{\circ} \mathrm{C} /\right.$ year $)$

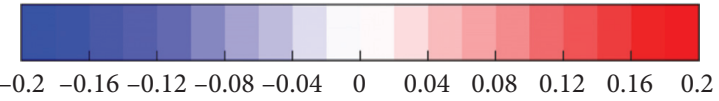

(b)

FIGURE 8: Spatial patterns of the SAT trends derived from the estimated SAT datasets during (a) 1960-1989 and (b) 1990-2019, respectively. The trend on each grid is calculated using the Mann-Kendall trend test method [61].

(trend $=-0.10 \sim 0^{\circ} \mathrm{C} /$ year; $p=0.03 \sim 0.41$ ). Only the western coast of the Ross Sea and the eastern and northern coast of the Weddell Sea showed a warming trend (trend $=0 \sim 0.08^{\circ} \mathrm{C} /$ year; $\quad p=0.06 \sim 0.44$ ). In addition, Figure $8(\mathrm{~b})$ shows that almost the entire Antarctic continent showed a warming trend during 1990-2019 
(trend $=0 \sim 0.10^{\circ} \mathrm{C} /$ year; $p=0.04 \sim 0.42$ ) with a peak over the higher latitude areas of the continent, indicating that the warming rate increased with latitude during 1990-2019. Only a small portion of the eastern seaboard showed a weak cooling trend (trend $=-0.02 \sim 0^{\circ} \mathrm{C} /$ year; $p=0.35 \sim 0.49$ ). The above comparisons demonstrate that there are spatiotemporal inconsistencies in the SAT trends over the Antarctic continent during the two periods and that the Antarctic SAT trends depend on the time period and the spatial area over which they are computed. For example, the highest cooling rate is found over the central part of the eastern Antarctic continent, while the highest warming rate is over the higher latitudes of the Antarctic continent. The cooling rates during 1960-1989 are greater than the warming rates during 1990-2019. Finally, the mechanism driving the spatiotemporal inconsistencies in the SAT trends over the Antarctic continent during the two periods should be further investigated with the aid of a fully coupled climate model; however, this analysis is beyond the main aim of this study and will be addressed in future work.

\section{Discussion}

Generally, the interpolation errors for climate variables decrease monotonically with the increase of the stationbased data used [18, 19, 23, 59]. The interpolation errors of MLR and BPANN are consistent with this rule (see Figure 5). However, the interpolation errors of GA-BPANN showed a decreasing trend before 1980, an increasing trend between 1980 and 2003, and a decreasing trend after 2003. Namely, the interpolation errors of GA-BPANN do not decrease monotonically with the increase of the used station-based data. Nonetheless, the interpolation errors of GA-BPANN are always apparently smaller than those of the MLR and BPANN. The reasons for this situation may be attributed to the fact that the number and spatial distribution of stations in different months are time-varied, but the parameter values of GA (see Figure 3) are invariant in all months. Additionally, the parameter values affect the optimization performance of the GA [46, 47]. Consequently, the GA might not search the optimal connection weights and thresholds for some months under these invariant parameter values, leading to the interpolation accuracies of GABPANN in the corresponding months that did not reach the expected optimization effect. But GA-BPANN is still superior to the traditional BPANN with random connections and thresholds and the MLR linearly linking the SAT and geographical factors. Thus, an straightforward approach to further improve the performance of GA-BPANN is to adopt time-varied parameter values in the searching process of the GA. Specifically, the GA uses multiple groups of parameter values in each month, which are randomly sampled from the empirical ranges of parameters, to search the optimal weights and thresholds. In each month, a cluster of GABPANN interpolation models are trained using the same training sample but different GA parameter values, and we only select the optimal GA-BPANN interpolation model to estimate the SAT field of that month. This approach ensures that the monthly GA-BPANN interpolation model can be adapted to the sample data in the corresponding month as much as possible, as long as there are enough groups of parameter values. However, the number of parameter groups cannot be infinite because more parameter groups used means more time consumption is needed.

In addition, as with previous SAT interpolation studies for other regions $[18,19,21-23,31,59]$, it usually needs to place the estimated SAT fields based on the GA-BPANN method in the context of previously published SAT datasets developed by traditional interpolation methods. However, some data-related issues stymied this attempt. In particular, although there exist several interpolation-based and widely used gridded SAT datasets, such as HadCRUT4 [24], BEST [25], GISTEMP [26], MLOST [27], and CRU TS [28], these datasets either omit the Antarctic region or have a large portion of missing values over the Antarctic continent. As a result, these data-related issues cannot allow comparing the estimated SAT data in this study with several widely used SAT interpolation data in terms of fully Antarctic SAT patterns. Nonetheless, a previous study had generated an Antarctic annual mean surface temperature map (hereinafter, AAMSTM) using the MLR method based on 1175 Antarctic annual mean surface temperature datasets, including Antarctic ice-sheet temperature data, $10 \mathrm{~m}$ borehole temperature, and automatic weather station data [54]. The AAMSTM demonstrates that the Antarctic annual mean surface temperature has a minimum of below $-55^{\circ} \mathrm{C}$ over central East Antarctica, features strong elevation-dependent variations, and varies from $-20^{\circ} \mathrm{C}$ to $-10^{\circ} \mathrm{C}$ over the coastal regions. The SAT patterns and magnitudes reflected in AAMSTM are highly consistent with those of the Antarctic SAT showed in Figure 7, indicating the reliability of the GA-BPANN-estimated SAT fields in this study.

Only three geographic factors (i.e., longitude, latitude, and elevation), which were found to be the main factors affecting monthly SAT distribution and variation at continental scales in several previous studies, were considered for estimating the Antarctic SAT fields in this study. However, the mechanisms driving SAT distribution and variation are very complicated in space and time domains $[18,55,59]$, and there may be some other factors that have not yet been evaluated such as land surface type, air humidity, wind speed, wind direction, and distance from the coastline; particularly, sea surface temperature and atmospheric circulation have been regarded as important factors affecting the long-term trend of the monthly and annual mean SAT $[62,63]$. However, this issue is beyond the scope of this study and will be explored in future work. In addition, the topography of the Antarctic inland is very complex; in this case, more station-based data are needed to describe the local relationship between SAT and topography factors $[18,55,59]$. In this study, 82 station-based SAT data over the Antarctic were used in Antarctic SAT interpolation, which is far more than the number of the Antarctic stations used in previously published SAT datasets [24-26, 64] mainly because the GHCNmV4 dataset integrated more historical station-based data. However, as can be seen from Figure 1, most of the 82 stations are distributed along the Antarctic 
coastline, and the stations over the Antarctic inland are still very sparse and uneven, which may lead to greater uncertainty in the SAT interpolation over the Antarctic inland [59]. However, this intrinsic deficiency associated with the distributions of the Antarctic meteorological stations cannot be overcome by current interpolation methods, which is a major challenge for Antarctic SAT interpolation and drives the stakeholders to develop new interpolation methods based on sparse and uneven historical stations.

The geographical factor samples used for training interpolation models and estimating SAT fields generally are extracted from DEM data; accordingly, the spatial resolution and accuracy of DEM data substantially affect the interpolation accuracy $[19,23,59]$. A DEM data with finer resolution and accuracy would improve the accuracy of climate interpolation, particularly in areas with complicated topography such as the Antarctic continent [54] because it can provide a better topographical description and is beneficial to constructing a more accurate statistical relationship between climate variable and geographical factors. Therefore, applying the most appropriate DEM data to extract geographical factors is critically important and indispensable. The Antarctic DEM data used in this study has the finest spatial resolution among several existing Antarctic DEM data, and the quality has been rigorously tested (see details at https://data.tpdc.ac.cn/en/ data/). Therefore, this DEM data enable to minimize the Antarctic SAT interpolation errors as much as possible. However, the Antarctic continent is different from other continents in that it is completely covered by ice and snow that have been changing in recent decades under the global warming $[65,66]$, meaning that the Antarctic elevations also have been changing over time as the ice and snow are melting and freezing $[67,68]$ compared with other ice-free continents with stable elevations. Actually, the Antarctic DEM data used in this study represents the multiyear mean elevations during 1998-2008. It is bound to bring errors to interpolation results if extracting elevation values from the multiyear mean DEM to construct monthly training samples and interpolation samples during 1960-2019. However, there is no monthly and long-term Antarctic DEM data; this is challenging in Antarctic SAT interpolation when DEM-based geographical factors must be considered.

Finally, spatial interpolation is a complicated issue, and each interpolation method has its own specific assumptions, applicable conditions, merits, and drawbacks. Although GABPANN performed well in the Antarctic SAT interpolation, it may not perform well in other areas of the globe with different station-based SAT data and different climate variables. Spatial interpolation should be carried out according to the geographical and topographical characteristics of the study area (e.g., mountainous area, plain, plateau, inland, and coastal) and the characteristics of the station-based data (e.g., data quality, data quantity, evenness of spatial distribution, temporal continuity and physical properties of the variables). Thus, the most suitable method and datasets should be utilized in the specific area when performing spatial interpolation.

\section{Conclusions}

Accurately and fully understanding the Antarctic SAT variations helps improve global climate change predictions. However, due to data availability issues, the Antarctic SAT variations during the last decades remain controversial. This controversy has motivated stakeholders to generate a widely accepted, high-quality, and spatiotemporally continuous SAT dataset over the Antarctic that could help to fully understand the Antarctic SAT variations during the last decades. Spatial interpolation is an alternative approach used to generate spatiotemporally continuous and high-quality SAT data based on limited station-based SAT observations. This study introduced a promising spatial interpolation method, i.e., GA-BPANN, which is a BPANN optimized by GA. The GA-BPANN was compared with BPANN and MLR to estimate the monthly SAT fields of the Antarctic continent during 1960-2019. Validations demonstrated that the interpolation performance of GA-BPANN is better than that of BPANN and MLR. GA-BPANN improved the representation of the nonlinear relationship between SAT and the geographic factors modulating the SAT distribution, which could not be expressed by MLR. GA-BPANN also avoids falling easily into a local optimum, which is a shortcoming of the BPANN approach.

Based on the estimated SAT fields of the Antarctic continent obtained with GA-BPANN, the temporal and spatial variations of the Antarctic SAT during 1960-2019 were analyzed. The Antarctic annual SAT experienced a significant cooling trend during 1960-1989 and a significant warming trend during 1990-2019. The SAT in most months showed cooling trends during 1960-1989 and warming trends during 1960-1989, though the significance levels and rates varied in different months. The spatial distributions of the mean SAT fields during 1960-1989 and 1990-2019 show almost identical patterns over the Antarctic continent. The Antarctic SAT decreased with latitude and distance from the coastline, and the eastern Antarctic continent was overall colder than the west Antarctic continent. The SAT over most of the Antarctic continent, including the Antarctic Peninsula, has undergone a cooling trend during 1960-1989, with a peak over the central part of the eastern Antarctic continent. Only the western coast of the Ross Sea and the eastern and northern coast of the Weddell Sea showed warming trends. In addition, almost the entire Antarctic continent showed a warming trend during 1990-2019, with a peak over the higher latitudes of the Antarctic continent. These results confirmed the existence of spatiotemporal inconsistencies in the SAT trends over the Antarctic continent during the two climatological periods examined. However, it is noted that a weakness of this study is the inability to make physical explanations on the spatiotemporal inconsistencies in the Antarctic SAT trends during the two climatological periods because addressing this issue requires to conduct complicated attribution experiments with the aid of coupled climate models, which substantially goes beyond the main scope of this research.

In summary, this study confirmed that the introduced GA-BPANN substantially improves the interpolation 
accuracies in the estimation of Antarctic SAT fields compared with BPANN and MLR. The spatiotemporal variations of the Antarctic SAT during 1960-2019 were analyzed based on the estimated monthly SAT fields generated by the GABPANN method. Moreover, some prospects for improving the skill of spatial interpolation were also discussed. The Antarctic SAT dataset generated by this study can provide a data basis for studying Antarctic climate change, validating numerical climate models, and guiding Antarctic field research activities (e.g., drilling ice core and planning meteorological stations). The conclusions of this study are also expected to give new insights into the fields of spatial interpolation methods and Antarctic SAT change during the last decades.

\section{Data Availability}

The GHCNmV4 dataset was downloaded from the National Climatic Data Centre (https://www.ncdc.noaa.gov/dataaccess/land-based-station-data/land-based-datasets/globalhistorical-climatology-network-monthly-version-4). The DEM data were downloaded from the National Tibetan Plateau Data Centre (TPDC) (https://data.tpdc.ac.cn/en/ data/). The monthly gridded SAT dataset for the Antarctic continent during 1960-2019 was generated by this study, and source codes used in this study are directly available from the author (e-mail: mfang@lzb.ac.cn).

\section{Conflicts of Interest}

The author declares that there are no conflicts of interest regarding the publication of this study.

\section{Acknowledgments}

This work was jointly supported by the Strategic Priority Research Program of the Chinese Academy of Sciences (Grant no. XDA19070103), the National Key R\&D Program of China (Grant no. 2017YFA0603302), the National Science Foundation of China project under (Grant no. 41701046), and the CAS "Light of West China" Program.

\section{References}

[1] J. J. Cassano, P. Uotila, and A. Lynch, "Changes in synoptic weather patterns in the polar regions in the twentieth and twenty-first centuries, part 2: Antarctic," International Journal of Climatology, vol. 26, no. 8, pp. 1027-1049, 2006.

[2] J. H. Oh, W. Park, H. G. Lim et al., "Impact of Antarctic meltwater forcing on East Asian climate under greenhouse warming," Geophysical Research Letters, vol. 47, no. 21, Article ID e2020GL089951, 2020.

[3] J. Feng, Y. Zhang, Q. Cheng, X. S. Liang, and T. Jiang, "Analysis of summer Antarctic sea ice anomalies associated with the spring Indian ocean dipole," Global and Planetary Change, vol. 181, Article ID 102982, 2019.

[4] M. R. England, L. M. Polvani, and L. Sun, "Robust Arctic warming caused by projected Antarctic sea ice loss," Environmental Research Letters, vol. 15, Article ID 104005, 2020.
[5] P. T. Doran, J. C. Priscu, W. B. Lyons et al., "Antarctic climate cooling and terrestrial ecosystem response," Nature, vol. 415, no. 6871, pp. 517-520, 2002.

[6] D. T. Shindell and G. A. Schmidt, "Southern hemisphere climate response to ozone changes and greenhouse gas increases," Geophysical Research Letters, vol. 31, no. 18, Article ID L18209, 2004.

[7] B. Stenni, M. A. J. Curran, N. J. Abram et al., "Antarctic climate variability on regional and continental scales over the last 2000 years," Climate of the Past, vol. 13, no. 11, pp. 1609-1634, 2017.

[8] W. L. Chapman and J. E. Walsh, "A synthesis of Antarctic temperatures," Journal of Climate, vol. 20, no. 16, pp. 4096-4117, 2007.

[9] E. J. Steig, D. P. Schneider, S. D. Rutherford, M. E. Mann, J. C. Comiso, and D. T. Shindell, "Warming of the Antarctic ice-sheet surface since the 1957 international geophysical year," Nature, vol. 457, no. 7228, pp. 459-462, 2009.

[10] J. P. Nicolas and D. H. Bromwich, "New reconstruction of Antarctic near-surface temperatures: multidecadal trends and reliability of global reanalyses," Journal of Climate, vol. 27, no. 21, pp. 8070-8093, 2014.

[11] R. Mulvaney, N. J. Abram, R. C. A. Hindmarsh et al., "Recent Antarctic peninsula warming relative to Holocene climate and ice-shelf history," Nature, vol. 489, no. 7414, pp. 141-144, 2012.

[12] D. Bozkurt, D. H. Bromwich, J. Carrasco et al., "Recent nearsurface temperature trends in the Antarctic peninsula from observed, reanalysis and regional climate model data," Advances in Atmospheric Sciences, vol. 37, no. 5, pp. 59-75, 2020.

[13] J. Turner, H. Lu, I. White et al., "Absence of 21st century warming on Antarctic peninsula consistent with natural variability," Nature, vol. 535, no. 7612, pp. 411-415, 2016.

[14] M. A. Lazzara, G. A. Weidner, L. M. Keller, J. E. Thom, and J. J. Cassano, "Antarctic automatic weather station program: 30 years of polar observation," Bulletin of the American Meteorological Society, vol. 93, no. 10, pp. 1519-1537, 2012.

[15] J. Turner, G. J. Marshall, K. Clem, S. Colwell, T. Phillips, and H. Lu, "Antarctic temperature variability and change from station data," International Journal of Climatology, vol. 40, no. 6, pp. 2986-3007, 2019.

[16] D. P. Schneider and D. B. Reusch, "Antarctic and Southern ocean surface temperatures in CMIP5 models in the context of the surface energy budget," Journal of Climate, vol. 29, no. 5, pp. 1689-1716, 2016.

[17] B. Huai, Y. Wang, M. Ding, J. Zhang, and X. Dong, "An assessment of recent global atmospheric reanalyses for Antarctic near surface air temperature," Atmospheric Research, vol. 226, pp. 181-191, 2019.

[18] K. Stahl, R. D. Moore, J. A. Floyer, M. G. Asplin, and I. G. McKendry, "Comparison of approaches for spatial interpolation of daily air temperature in a large region with complex topography and highly variable station density," Agricultural and Forest Meteorology, vol. 139, no. 3-4, pp. 224-236, 2006.

[19] A. O. Arowolo, A. K. Bhowmik, W. Qi, and X. Deng, "Comparison of spatial interpolation techniques to generate high-resolution climate surfaces for Nigeria," International Journal of Climatology, vol. 37, no. S1, pp. 179-192, 2017.

[20] A. Di Piazza, F. L. Conti, L. V. Noto, F. Viola, and G. La Loggia, "Comparative analysis of different techniques for spatial interpolation of rainfall data to create a serially complete monthly time series of precipitation for Sicily, Italy," 
International Journal of Applied Earth Observation and Geoinformation, vol. 13, no. 3, pp. 396-408, 2011.

[21] S. Vicente-Serrano, M. Saz-Sánchez, and J. Cuadrat, "Comparative analysis of interpolation methods in the middle Ebro valley (Spain): application to annual precipitation and temperature," Climate Research, vol. 24, no. 2, pp. 161-180, 2003.

[22] G. Hudson and H. Wackernagel, "Mapping temperature using Kriging with external drift: theory and an example from Scotland," International Journal of Climatology, vol. 14, no. 1, pp. 77-91, 2010.

[23] B. Bai, X. J. Chen, and J. Yu, "A study of spatial interpolation of Gansu air temperature based on ArcGIS," Advanced Materials Research, vol. 518-523, pp. 1359-1362, 2012.

[24] C. P. Morice, J. J. Kennedy, N. A. Rayner et al., "Quantifying uncertainties in global and regional temperature change using an ensemble of observational estimates: the HadCRUT4 data set," Journal of Geophysical Research: Atmospheres, vol. 117, Article ID D08101, 2012.

[25] R. Rohde, R. Muller, R. Jacobsen et al., "Berkeley earth temperature averaging process," Geoinformatics \& Geostatistics An Overview, vol. 1, no. 2, pp. 1-13, 2013.

[26] J. Hansen, R. Ruedy, M. Sato et al., "Global surface temperature change," Reviews of Geophysics, vol. 48, no. 4, Article ID RG4004, 2010.

[27] T. M. Smith, R. W. Reynolds, T. C. Peterson, and J. Lawrimore, "Improvements to NOAA's historical merged land-ocean surface temperature analysis (1880-2006)," Journal of Climate, vol. 21, no. 10, pp. 2283-2296, 2008.

[28] I. Harris, P. D. Jones, T. J. Osborn, and D. H. Lister, "Updated high-resolution grids of monthly climatic observations - the CRU TS3.10 dataset," International Journal of Climatology, vol. 34, no. 3, pp. 623-642, 2014.

[29] K. Cowtan and R. G. Way, "Coverage bias in the HadCRUT4 temperature series and its impact on recent temperature trends," Quarterly Journal of the Royal Meteorological Society, vol. 140, no. 683, pp. 1935-1944, 2014.

[30] J. Li, A. D. Heap, A. Potter, and J. J. Daniell, “Application of machine learning methods to spatial interpolation of environmental variables," Environmental Modelling \& Software, vol. 26, no. 12, pp. 1647-1659, 2011.

[31] P. Annalisa, C. Francesco, V. Francesco, E. Emanuele, and N. Leonardo, "Comparative analysis of spatial interpolation methods in the Mediterranean area: application to temperature in Sicily," Water, vol. 7, no. 12, p. 1866, 2015.

[32] J. C. S. Júnior, V. Medeiros, C. Garrozi, A. Montenegro, and G. E. Gonalves, "Random forest techniques for spatial interpolation of evapotranspiration data from Brazilian's Northeast," Computers and Electronics in Agriculture, vol. 166, Article ID 105017, 2019.

[33] P. J. Mitchell, M. A. Spence, J. Aldridge, A. T. Kotilainen, and M. Diesing, "Sedimentation rates in the Baltic sea: a machine learning approach," Continental Shelf Research, vol. 214, Article ID 104325, 2021.

[34] A. T. C. Goh, "Back-propagation neural networks for modeling complex systems," Artificial Intelligence in Engineering, vol. 9, no. 3, pp. 143-151, 1995.

[35] B. T. Pham, D. Tien Bui, I. Prakash, and M. B. Dholakia, "Hybrid integration of multilayer perceptron neural networks and machine learning ensembles for landslide susceptibility assessment at Himalayan area (India) using GIS," Catena, vol. 149, pp. 52-63, 2017.

[36] Q. Li, J. C. Cheng, and Y. M. Hu, "Spatial interpolation of soil nutrients based on BP neural network," Agricultural Science \&Technology, vol. 15, no. 3, pp. 506-511, 2014.
[37] S. Lee, H. An, S. Yu, and J. J. Oh, "Creating an advanced backpropagation neural network toolbox within GIS software," Environmental Earth Sciences, vol. 72, no. 8, pp. 3111-3128, 2014.

[38] Z. Jia, S. Zhou, Q. Su, H. Yi, and J. Wang, "Comparison study on the estimation of the spatial distribution of regional soil metal(loid)s pollution based on Kriging interpolation and BP neural network," International Journal of Environmental Research and Public Health, vol. 15, no. 1, Article ID 34, 2018.

[39] D. M. Merkulov and I. V. Oseledets, "Empirical study of extreme overfitting points of neural networks," Journal of Communications Technology and Electronics, vol. 64, no. 12, pp. 1527-1534, 2019.

[40] A. O. Ibrahim, S. M. Shamsuddin, A. Y. Saleh, A. Ahmed, M. A. Ismail, and S. Kasim, "Backpropagation neural network based on local search strategy and enhanced multi-objective evolutionary algorithm for breast cancer diagnosis," International Journal on Advanced Science, Engineering and Information Technology, vol. 9, no. 2, pp. 609-615, 2019.

[41] L. A. Muhammed, "Impact of mutation weights on training backpropagation neural networks," International Journal of Electronics Communication and Computer Engineering, vol. 5, no. 4, pp. 779-781, 2014.

[42] S. Ding, C. Su, and J. Yu, “An optimizing BP neural network algorithm based on genetic algorithm," Artificial Intelligence Review, vol. 36, no. 2, pp. 153-162, 2011.

[43] A. Bader, "Simulation design of a backpropagation neural system of sensor network trained by particle swarm optimization," International Journal of Scientific and Engineering Research, vol. 7, no. 4, pp. 576-582, 2016.

[44] T. Liu and S. Yin, "An improved particle swarm optimization algorithm used for BP neural network and multimedia courseware evaluation," Multimedia Tools and Applications, vol. 76, no. 9, pp. 11961-11974, 2017.

[45] I. Aljarah, H. Faris, and S. Mirjalili, "Optimizing connection weights in neural networks using the whale optimization algorithm," Soft Computing, vol. 22, no. 1, pp. 1-15, 2018.

[46] D. E. Goldberg, Genetic Algorithm in Search Optimization and Machine Learning, Vol. 8, Addison Wesley, Boston, MA, USA, 1989.

[47] J. Wu, Y. Cheng, C. Liu, I. Lee, and W. Huang, "A BP neural network based on GA for optimizing energy consumption of copper electrowinning," Mathematical Problems in Engineering, vol. 2020, Article ID 1026128, 10 pages, 2020.

[48] Y. Liang, C. Ren, H. Wang, Y. Huang, and Z. Zheng, "Research on soil moisture inversion method based on GA-BP neural network model," International Journal of Remote Sensing, vol. 40, no. 5-6, pp. 2087-2103, 2018.

[49] Z. Liu, X. Liu, K. Wang et al., "GA-BP neural network-based strain prediction in full-scale static testing of wind turbine blades," Energies, vol. 12, no. 6, Article ID 1026, 2019.

[50] Y. Peng, W. Xiang, K. A. Dawson et al., "Short-term traffic volume prediction using GA-BP based on wavelet denoising and phase space reconstruction," Physica A: Statistical Mechanics and Its Applications, vol. 549, Article ID 123913, 2020.

[51] L. Wang and X. Bi, "Risk assessment of knowledge fusion in an innovation ecosystem based on a GA-BP neural network," Cognitive Systems Research, vol. 66, pp. 201-210, 2021.

[52] M. J. Menne, C. N. Williams, B. E. Gleason, J. J. Rennie, and J. H. Lawrimore, "The global historical climatology network monthly temperature dataset, version 4," Journal of Climate, vol. 31, no. 24, pp. 9835-9854, 2018.

[53] H. Feidas, A. Karagiannidis, S. Keppas et al., "Modeling and mapping temperature and precipitation climate data in 
Greece using topographical and geographical parameters," Theoretical \& Applied Climatology, vol. 118, no. 1-2, pp. 133-146, 2014.

[54] Y. Wang and S. Hou, "A new interpolation method for Antarctic surface temperature," Progress in Natural Science, vol. 19, no. 12, pp. 1843-1849, 2009.

[55] N. Takayama, S. Hayakawa, and S. Onomoto, "Development of frost damage prediction technique using digital elevation model (DEM) in air temperature estimation," Journal of Agricultural Meteorology, vol. 60, no. 5, pp. 873-876, 2016.

[56] V. Garzón-Machado, R. Otto, and M. J. del Arco Aguilar, "Bioclimatic and vegetation mapping of a topographically complex oceanic island applying different interpolation techniques," International Journal of Biometeorology, vol. 58, no. 5, pp. 887-899, 2014.

[57] E. Pi, N. Mantri, S. M. Ngai, H. Lu, and L. Du, "BP-ANN for fitting the temperature-germination model and its application in predicting sowing time and region for bermudagrass," PLoS One, vol. 8, no. 12, Article ID e82413, 2013.

[58] M. Madić and M. Radovanović, "Methodology of developing optimal BP-ANN model for the prediction of cutting force in turning using early stopping method," Facta Universitatis: Mechanical Engineering, vol. 9, no. 1, pp. 21-32, 2011.

[59] C. Xu, J. Wang, and Q. Li, "A new method for temperature spatial interpolation based on sparse historical stations," Journal of Climate, vol. 31, no. 5, pp. 1757-1770, 2018.

[60] R. Lindsay, M. Wensnahan, A. Schweiger, and J. Zhang, "Evaluation of seven different atmospheric reanalysis products in the Arctic," Journal of Climate, vol. 27, no. 7, pp. 2588-2606, 2014.

[61] M. Gocic and S. Trajkovic, "Analysis of changes in meteorological variables using Mann-Kendall and Sen's slope estimator statistical tests in Serbia," Global and Planetary Change, vol. 100, pp. 172-182, 2013.

[62] S. Chen and R. Wu, "Interdecadal changes in the relationship between interannual variations of spring north Atlantic SST and Eurasian surface air temperature," Journal of Climate, vol. 30, no. 10, pp. 3771-3787, 2017.

[63] R. Wu and S. Chen, "What leads to persisting surface air temperature anomalies from winter to following spring over the mid-high latitude Eurasia?" Journal of Climate, vol. 33, no. 14, pp. 5861-5883, 2020.

[64] M. B. Giovinetto, N. M. Waters, and C. R. Bentley, "Dependence of Antarctic surface mass balance on temperature, elevation, and distance to open ocean," Journal of Geophysical Research, vol. 95, no. D4, pp. 3517-3531, 1990.

[65] F. S. Paolo, H. A. Fricker, and L. Padman, "Volume loss from Antarctic ice shelves is accelerating," Science, vol. 348, no. 6232, pp. 327-331, 2015.

[66] E. Rignot, "Mass balance of east Antarctic glaciers and ice shelves from satellite data," Annals of Glaciology, vol. 34, no. 1, pp. 217-227, 2002.

[67] D. J. Wingham, A. J. Ridout, R. Scharroo, R. J. Arthern, and C. K. Shum, "Antarctic elevation change from 1992 to 1996," Science, vol. 282, no. 5388, pp. 456-458, 1998.

[68] T. A. Scambos, R. E. Bell, R. B. Alley et al., "How much, how fast?: a science review and outlook for research on the instability of Antarctica's Thwaites Glacier in the 21st century," Global and Planetary Change, vol. 153, pp. 16-34, 2017. 